\title{
Research on Raw Material Consumption and its Socioeconomic Divers of Shenyang
}

\author{
HeMing Wang ${ }^{1, A^{*}}$, FengMei Ma ${ }^{2, D}$, Shen Zhao ${ }^{1, B}$, \\ Jian Wang ${ }^{1, \mathrm{C}}$, Qiang Yue ${ }^{1, \mathrm{E}}$, and Tao Du ${ }^{1, \mathrm{~F}}$ \\ ${ }^{1}$ State Environmental Protection Key Laboratory of Eco-Industry, Northeastern University, China \\ ${ }^{2}$ College of Economics and Management, Shenyang Agricultural University, China \\ awanghm@mail.neu.edu.cn, bmafm08@hotmail.com, 'czhaoshen_2016@hotmail.com, \\ 'wangjian_2016@hotmail.com, eyueq@mail.neu.edu.cn, ${ }^{,}$dut@mail.neu.edu.cn. *Corresponding \\ author
}

Keywords: Raw material consumption ; Structural decomposition analysis ; Material Flow Analysis ; Input-output analysis ; Shenyang.

\begin{abstract}
China's resource consumption has been increased rapidly with the development of economy. As one of China's most important industrializing cities, Shenyang faces even severer situation of resource restriction. It is important to analyze Raw Material Consumption (RMC) of Shenyang and its socioeconomic divers before designing future environmental and economic plans. In this study, we calculate the RMC of Shenyang during 2002-2012, and then use Structural Decomposition Analysis (SDA) to find the driving factors of it. Results show that RMC of Shenyang was increased by $160 \%$ from 93 million tons to 247 million tons during the studied period. Construction and heavy manufacture sectors contributed the most to the resource consumption. In terms of driving factors, final demand level was the most significant one, and production structure partly impeded the increasing of RMC. It is suggested that more attention should be paid to construction investment and improvement of production structure to control the increase of resource use.
\end{abstract}

\section{Introduction}

Achieving the decoupling between GDP growth and raw material consumption (RMC) is a major environmental issue in China[1,2]. As an important industrial city in China, Shenyang faces even severe challenge. Shenyang is the capital city in Liaoning province and industrial center in northeastern China. Moreover, it is a big city with $12948 \mathrm{~km}^{2}$ areas and more than 8 million people[3]. After China implemented the plan of revitalizing the old industrial bases in northeastern China, Shenyang's GDP has increased by 3.7 times from 140 billion yuan to 660 billion yuan during 2002-2012. But revitalizing of industry could lead to huge amount of RMC. Therefore, it is important to find factors that drove the RMC to solve the environment problem in Shenyang. Structural decomposition analysis (SDA) is a popular method for analyzing the driving factors of RMC. Most previous studies have focused on national and provincial levels[4,5]. However, quite few study focuses on city's level to analyze RMC in China, and this research could be regarded as one of the first attempts. In this study, we analyze RMC of Shenyang during 2002-2012 and explore its socioeconomic divers in order to help policymakers understand how the economic transition influences its materialization process. Our findings may be generalizable to other industrializing cities with similar development path.

\section{Methods and Data}

\section{Structural Decomposition Analysis}

SDA is a common method to explore the resource consumption and environmental pressure in environmental field[6]. Under input-output analysis model, resource consumption and environment pressure can be expressed mathematically as[7] 


$$
e=F(I-A)^{-1} y_{d}=F L y_{d}
$$

In this study, $e$ can be expressed as RMC in each sector. $F$ stands for the direct resource consumption for unitary output of each sector. $I$ is the identity matrix. $A$ is the coefficient matrix, the element $a_{i j}$ can be express as the input from sector $i$ directly demand to produce unitary output from sector $j . L=(I-A)^{-1}$ is the Leontief inverse, the element $l_{i j}$ can be express as the input from sector $i$ directly and indirectly demand to produce unitary output from sector $j . y_{d}$ is the domestic final demand of each sector, including rural and urban household consumption, government consumption, and investment.

SDA is also a common method to quantify the contributions of RMC's diver factors and find the main one that leads to consumption changes[8,9]. When we focus on RMC changes, Eq. (1) can be further transformed as

$$
e=F L y_{d c} y_{d l}
$$

Where $y_{d c}$ stands for composition of domestic final demand from each sector, its element stands for percentage share of each sector in each category of final demand. $y_{d l}$ is the domestic final demand level, which indicates per capita final demand volume.

Then, we decompose RMC into four parts: material intensity $(F)$, production structure $(L)$, final demand composition $\left(y_{d c}\right)$, final demand level $\left(y_{d l}\right)$. Consumption changes between two years can be expressed as

$$
\Delta e=\Delta F L y_{d c} y_{d l}+F \Delta L y_{d c} y_{d l}+F L \Delta y_{d c} y_{d l}+F L y_{d c} \Delta y_{d l}
$$

Where $\Delta e$ is the account of RMC change between two years, the first term stands for RMC change due to the intensity of material directly consumed, the second term stands for RMC change due to production structure, the third and forth term stands for RMC change due to final demand composition and final demand level.

\section{Data Collection}

The data of raw material extract is from Shenyang Statistical Yearbooks[3]. Biomass includes primary crops, crop residues, fodder crops, grazed biomass and wood. Metal ores include iron ores and non-ferrous metal ores (copper ores, bauxite and so on). Non-metallic minerals include industrial material and bulk materials used primarily for construction. Fossil fuels include coal, crude oil and natural gas. Data of input-output tables of Shenyang in 2002, 2007, 2012 are from survey of Statistical Bureau of Shenyang City, and in order to remove the effect of deflation, we converted current prices into 2000 constant price[10].

\section{Results and Analysis}

\section{The Extraction and Consumption of Raw Materials}

Fig. 1 shows the extraction, consumption, (domestic) import and (domestic) export of raw materials in 2002, 2007 and 2012. During this period, Shenyang's material extraction increased continuously by $80 \%$ from 58 million tons to 105 million tons during 2002-2012. The average annual growth rate was around $6 \%$. Non-metallic minerals dominated the extraction, accounting for $44 \%$ in $2002,34 \%$ in 2007, and 52\% in 2012, respectively. During 2002-2007, the extraction of non-metallic minerals was decreased a little, whereas during 2007-2012, was rapidly increased by 1.2 times to 54 million tons.

The growth trend of material consumption is different from material extraction. It was increased by $18 \%$ during 2002-2007, and then it was rapidly increased by 1.23 times to 247 million tons during 2007-2012, with an average annual growth rate of $10 \%$. Non-metallic minerals consumption doubled, which contributed the main material consumption increment during 2002-2007. However, RMC was increased by $18 \%$ during this period. As a result, the proportion of Non-metallic minerals was rapidly increased from $34 \%$ in 2002 to $58 \%$ in 2007 . Although non-metallic minerals were increased by $34 \%$ during 2007-2012, metallic minerals became the largest contributor, which increased rapidly by 4.4 times to 97 million tons. At the same time, RMC increased by 136 million tons and 55\% of the increment came from metallic minerals. 


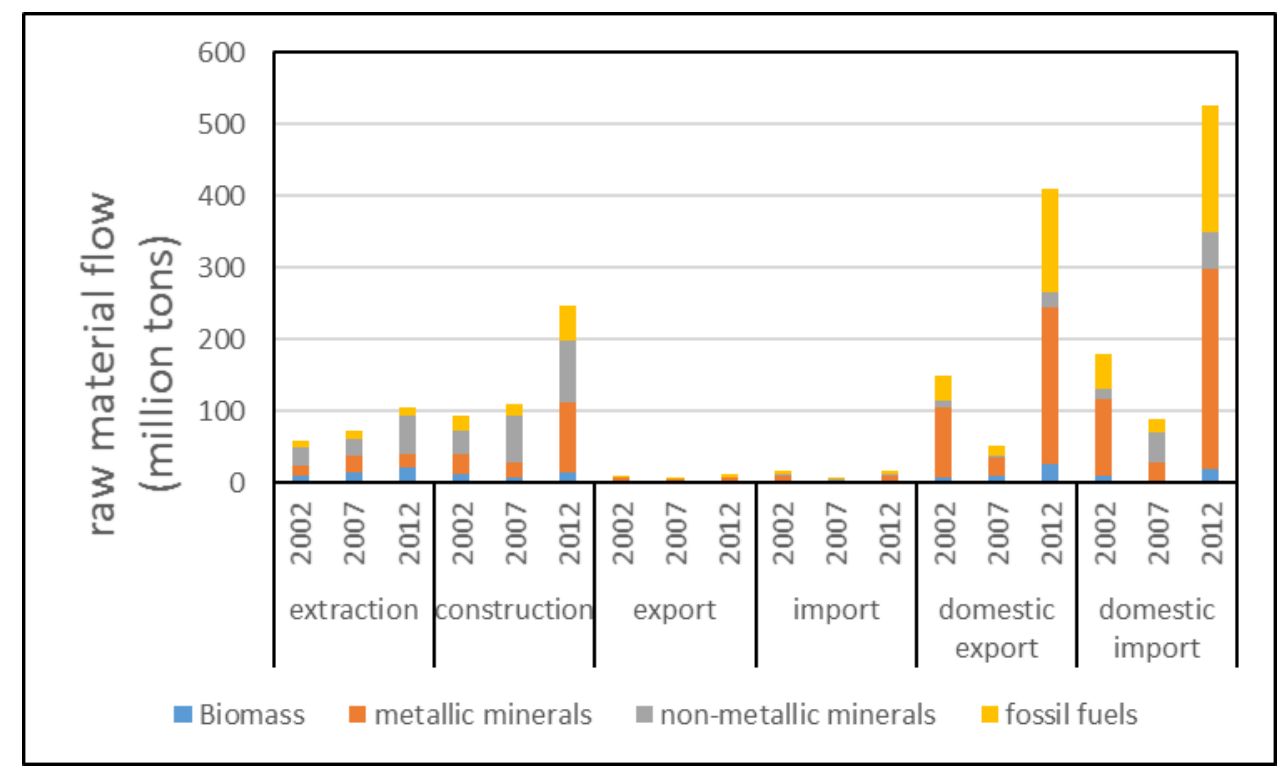

Figure 1. Shenyang's raw material flows in 2002, 2007 and 2012.

Fig. 1 also shows the (domestic) import and (domestic) export of raw materials in 2002, 2007 and 2012. In Shenyang, more than $90 \%$ of import and export are domestic. In particular, the account of domestic import and export is $97 \%$ of the total import and export in 2012. It mainly because Shenyang is the central city in northeast of China, connecting the northeast and north regions of China, and thus domestic trade dominates the trade business of Shenyang.

By comparing domestic import and export, we can find that Shenyang's material import was more than export, because Shenyang consumed larger amount of resources during its industrialization process. In addition, Shenyang's import and export nearly had the same rapid growth trend during 2007-2012. Within both import and export, metallic minerals and fossil fuels took up a big percentage. In $2012,54 \%$ and $35 \%$ of export and $53 \%$ and $34 \%$ of import were related to metallic minerals and fossil fuels. However, in the extraction and consumption, non-metallic minerals and metallic minerals took up a big percentage, because Shenyang itself had a good metallic and non-metallic resources endowment, although it cannot satisfy its industrialization need.

SDA of Shenyang's RMC (Heading 3). Fig.2 shows Shenyang's RMC driven by different final demand category. It can be found that the investment activity played an important role in metallic minerals, nonmetallic minerals and fossil fuels consumption. In 2012, 81\% of metallic minerals, $96 \%$ of non-metallic minerals and $65 \%$ of fossil fuels consumption were driven by investment activity. In addition to this, investment also dominated these resources consumption growth. During 2002-2012, approximately $87 \%$ of metallic minerals, $99 \%$ of non-metallic minerals and $81 \%$ of fossil fuels' consumption growth was contributed by investment activity. In addition to investment, urban household consumption was another important factor, which contributed $73 \%$ and $49 \%$ of biomass consumption in 2002 and 2012, respectively.

In this study, we combined 99 sectors into 12 main categories. Fig. 3 shows these sectors' RMC of Shenyang in 2002, 2007 and 2012. We can see that the construction sector had played an important role in Shenyang's metallic minerals, non-metallic minerals and fossil fuels consumption. In 2012, 56\% of metallic minerals, $95 \%$ of non-metallic minerals and $50 \%$ of fossil fuels consumption was in induced by construction. In addition to this, construction also dominated these resources consumption growth. During 2002-2012, approximately 64\% of metallic minerals, 99\% of non-metallic minerals and $67 \%$ of fossil fuels' consumption growth was caused by construction. Furthermore, agriculture was another main inducing factor in biomass consumption, and 40\% of biomass consumption in 2002 and $44 \%$ in 2012 was induced by that sector. Manufacturing was an important inducing factor for metallic minerals. In 2012, $24 \%$ of metallic minerals consumption was induced by manufacturing. 


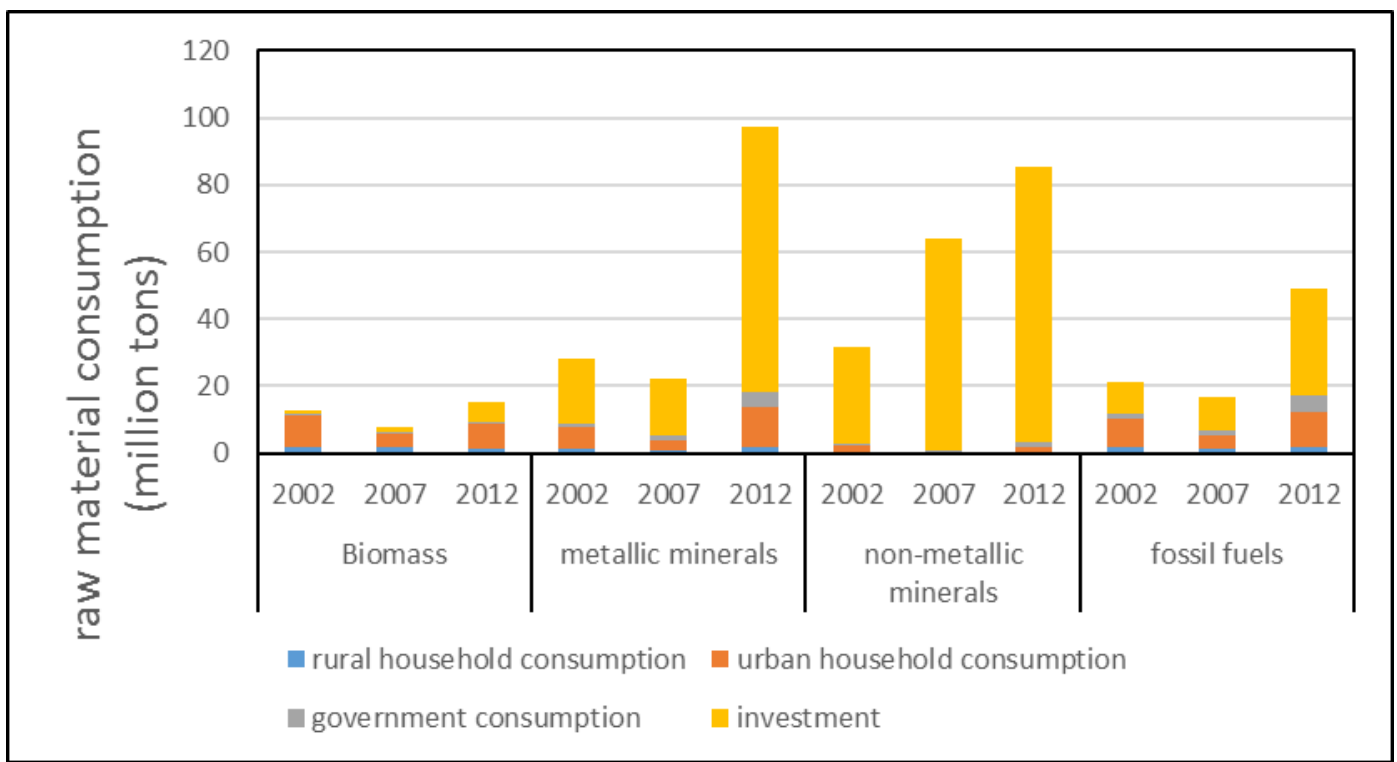

Figure 2. RMC by final demand category in 2002, 2007 and 2012.

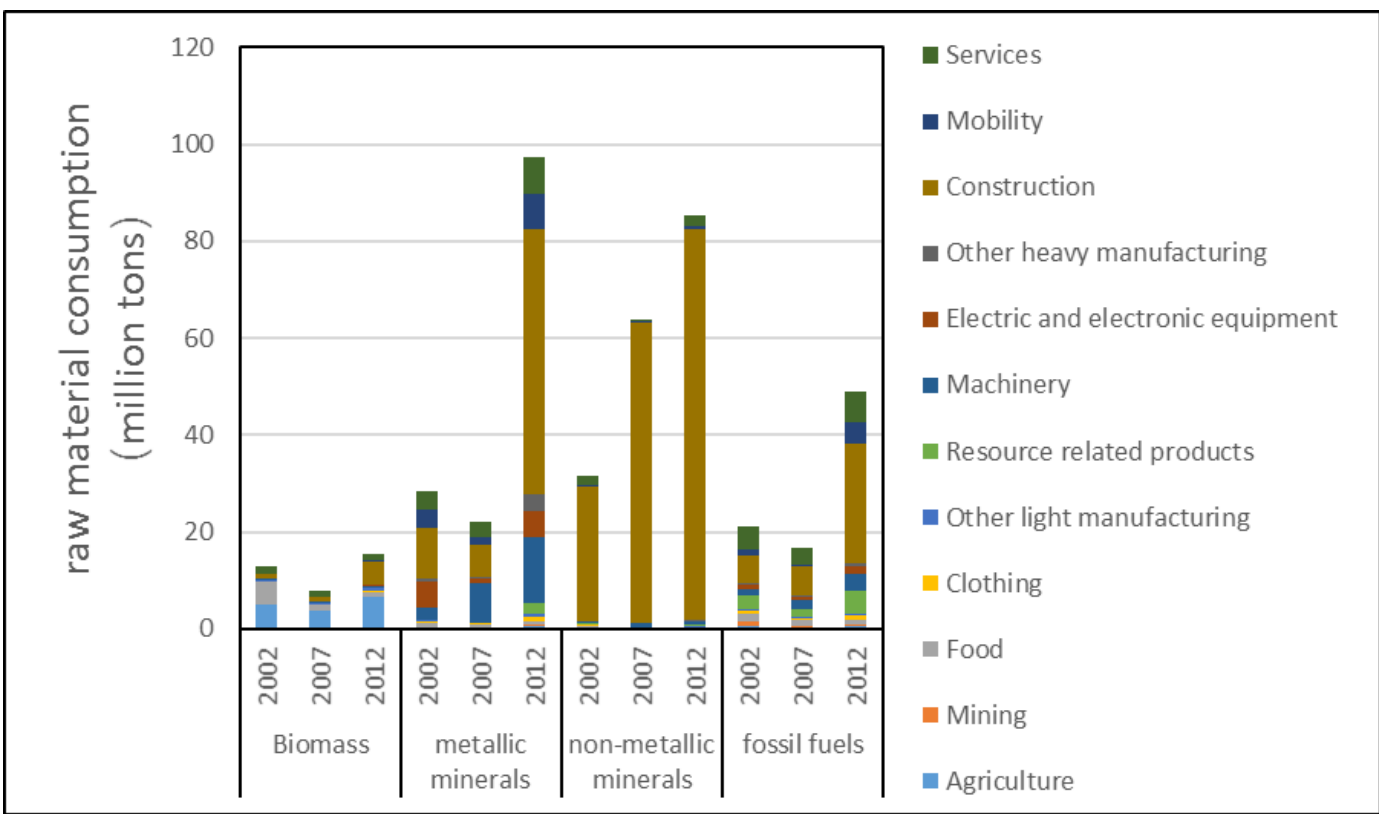

Figure 3. RMC by sectoral contributions category in 2002, 2007 and 2012. 


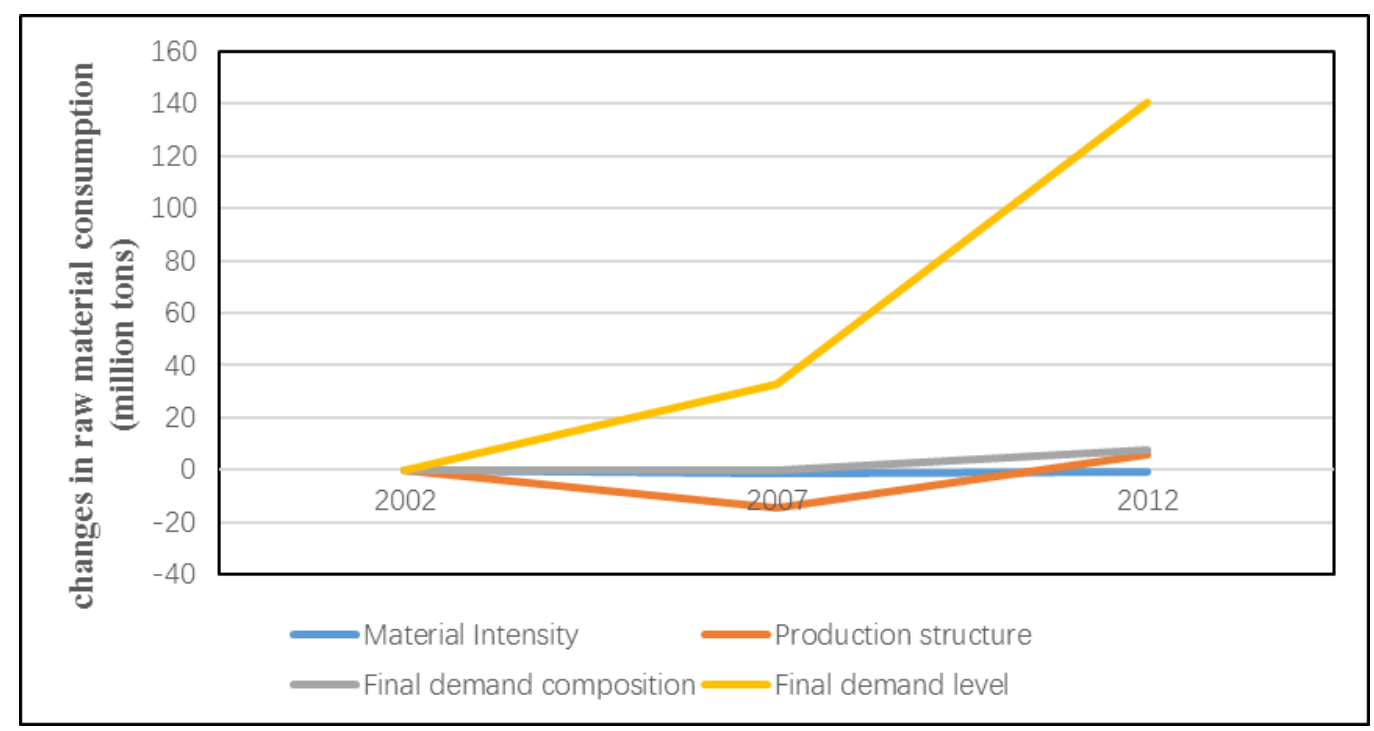

Figure 4. RMC changes by socioeconomic driving category in 2002, 2007 and 2012.

In SDA, we decompose RMC into four parts: material intensity, production structure, final demand composition, final demand level. Fig.4 shows these socioeconomic drivers' contribution in RMC growth. Final demand level was the main driving factor to promote consumption growth. During 2002-2007 and 2007-2012 periods, 33 million tons and 141 million tons of RMC were contributed by final demand level, and the actual increment of RMC was 17 million tons and 153 million tons, respectively. Production structure had impeded material consumption growth in a certain extent. Especially during 2002-2007, production structure had impeded 14 million tons' consumption growth.

\section{Conclusions}

This article has calculated RMC of Shenyang during 2002-2012, and analyzed its socioeconomic driving factors. The results have shown that Shenyang's RMC was increased rapidly by 1.6 times during this period. The construction and manufacture sectors and investment activity were the most main driving factors for the RMC growth. The results of SDA have shown that final demand level was the most important driving factor, whereas production structure partly impeded the increasing consumption growth. It is therefore suggested that more attention should be paid to the construction investment and improvement of production structure to control consumption growth.

\section{Acknowledgement}

This research was financially supported by the National Natural Science Foundation of China (71403175, 41401636, 71373003, and 51474067), Fundamental Research Funds for the Central Universities (N140204007), MOE Project of Humanities and Social Sciences (13YJCZH172, 13YJC790106), and General Research Project of Education Department of Liaoning Province (LZ2015034).

\section{References}

[1] H. Schandl, J. West. Material Flows and Material Productivity in China, Australia and Japan. J. Ind. Ecol. 16(2012) 352-364.

[2]H. Wang, Q. Yue, S. Hashimoto, Y. Moriguchi, and Z. Lu. Decoupling Analysis of Four Selected Countries: China, Russia, Japan and the USA during 2000-2007. J. Ind. Ecol. 17(2013) 618-629.

[3] Shenyang Statistical Yearbook 2013. Shenyang: Shenyang Statistics Press.

[4] S. Liang, Z. Liu, D. Crawford-Brown, Y. Wang, M. Xu. Decoupling Analysis and Socioeconomic Drivers of Environmental Pressure in China. Environ. Sci. Technol. 48(2014) 1103-1113. 
[5] H. Wang, S. Hashimoto, Y. Moriguchi, Q. Yue, Z. Lu. Resource use in growing China: Past trends, influence factors and future demand. J. Ind. Ecol. 16(2012) 481-492.

[6] R. Hoekstra, Van der Bergh, J. C. J. M. Structural decomposition analysis of physical flows in the economy. Environ. Resour. Econ. 23(2002) 357-378.

[7] Hertwich, E. G. Life cycle approaches to sustainable consumption: A critical review. Environ. Sci. Technol. 39(2005) 4673-4684.

[8]X. Tian, M. Chang, H. Tanikawa, F. Shi, H. Imura. Structural decomposition analysis of the carbonization process in Beijing: A regional explanation of rapid increasing carbon dioxide emission in China. Energy Pol. 53(2003) 279-286.

[9] A. Yamakawa, G. P. Peters. Structural decomposition analysis of greenhouse gas emissions in Norway 1990-2002. Econ. Syst. Res. 23(2011) 303-318.

[10] Q. Y. Liu, Z. L. Peng. China's constant price input-output table and relative analysis 1992-2005. China Statistics Press: Beijing, 2010. 